\title{
External Validation of Generic and Cancer-Specific Risk Stratification Tools in Patients With Pulmonary Embolism and Active Cancer
}

\author{
Erin R. Weeda, PharmDa; Jonathan T. Caranfa, PharmD ${ }^{\text {; }}$ Simon B. Zeichner, DOc; \\ Craig I. Coleman, PharmD ${ }^{d}$; Elaine Nguyen, PharmD, MPH'; and Christine G. Kohn, PharmD
}

\begin{abstract}
Background: Numerous risk stratification tools exist to predict early post-pulmonary embolism (PE) mortality; however, few were specifically designed for use in patients with cancer. This study sought to evaluate the performance of 3 cancer-specific (RIETE, POMPE-C, and Font criteria) and 3 generic (Hestia, Pulmonary Embolism Severity Index [PESI], and Geneva prognostic score [GPS]) risk stratification tools for predicting 30-day post-PE mortality in patients with active cancer. Methods: We identified consecutive, adult, objectively confirmed patients with PE and active cancer presenting to our institution from November 2010 to January 2014. We calculated the proportion of patients categorized as low or high risk by each of the 6 risk stratification tools and determined each tools' accuracy for predicting 30 -day allcause mortality. Results: A total of 124 patients with PE and active cancer were included (mean age, 66.2 years; $46.0 \%$ with concurrent deep vein thrombosis; $49.2 \%$ with metastatic disease; and $46.8 \%, 16.9 \%$, and $11.3 \%$ receiving chemotherapy, radiation, or both, respectively). Mortality at 30 days occurred in 25 patients (20.2\%). The cancer-specific tools (POMPE-C, RIETE, and Font criteria) categorized between $32 \%$ and $43 \%$ of patients as low risk and displayed sensitivities and specificities of $88.0 \%$ to $96.0 \%$ and $38.4 \%$ to $52.5 \%$, respectively. The generic PESI and Hestia tools had sensitivities $>96.0 \%$, but classified $<19 \%$ of patients as low risk; specificity of these tools were low (PESI, $6.1 \%$; Hestia, $23.2 \%$ ). Although the final noncancer tool, GPS, classified $43.5 \%$ of patients as low risk, it did so with a sensitivity of $52.0 \%$ and specificity of $42.4 \%$. Conclusions: When risk-stratifying PE in patients with active cancer, cancer-specific tools appeared to exhibit better prognostic accuracy than their generic counterparts. POMPE-C, RIETE, and the Font criteria identified a substantially greater proportion of patients with PE likely to survive to 30 days with comparable sensitivity to the generic tools.
\end{abstract}

Numerous risk stratification tools exist to predict early complications in patients with acute venous thromboembolism (VTE). ${ }^{1-6}$ Evidence suggests that these tools can potentially aid both physicians in making difficult patient disposition decisions and policy-makers in establishing hospital treatment guidelines. ${ }^{7,8}$ However,

From a Medical University of South Carolina College of Pharmacy, Charleston, South Carolina; bUniversity of Connecticut School of Medicine, Farmington, Connecticut; ' $E$ Emory Winship Cancer Institute, Atlanta, Georgia; dUniversity of Connecticut School of Pharmacy, Storrs, Connecticut; eIdaho State University College of Pharmacy, Meridian, Idaho; and fUniversity of Saint Joseph School of Pharmacy, Hartford, Connecticut. Submitted February 11, 2017; accepted for publication July 5, 2017. Dr. Coleman has disclosed that he has received grant funding and consultancy fees from Janssen Scientific Affairs, LLC; Bayer Pharma AG; and Boehringer-Ingelheim Pharmaceuticals, Inc. The remaining authors have disclosed that they have no financial interests, arrangements, affiliations, or commercial interests with the manufacturers of any products discussed in this article or their competitors. few tools were specifically designed for use in patients with active cancer.

Patients with cancer who develop an acute VTE are at increased risk for adverse outcomes. ${ }^{9,10}$ Consequently, many generic (ie, non-cancer-specific) risk stratification tools include cancer as a variable, ${ }^{2,3}$ but this could

Author contributions: Study concept and design: Weeda, Kohn, Coleman, Nguyen. Data acquisition: Weeda, Kohn, Coleman, Nguyen. Data analysis and interpretation: Weeda, Kohn, Coleman, Nguyen. Manuscript preparation: Weeda, Caranfa, Zeichner, Kohn, Coleman, Nguyen. Critical revision: Weeda, Caranfa, Zeichner, Kohn, Coleman, Nguyen. Administrative, technical or material support: Weeda, Kohn, Coleman. Study supervision: Kohn. Kohn had full access to all the study data and takes full responsibility for the integrity of the data and the accuracy of the data analysis.

Correspondence: Christine G. Kohn, PharmD, University of Saint Joseph School of Pharmacy, UCONN/Hartford Hospital Evidence-based Practice Center, 80 Seymour Street, Hartford, CT 06102.

E-mail: christine.kohn@hhchealth.org 
unnecessarily lead to classifying low-risk patients as high-risk due to their malignancy status. Because guidelines suggest the use of risk stratification tools to aid in decision-making for home or early discharge treatment, ${ }^{7,8}$ this misclassification of patients may result in an unneeded extension in hospital length of stay (LOS) and undue economic consequences, given that mean daily hospitalization costs for VTE in the United States have been shown to be upwards of $\$ 1,600$ USD. $^{11,12}$

In a retrospective cohort analysis, $\mathrm{Ahn}$ et $\mathrm{al}^{13}$ found that the generic Pulmonary Embolism Severity Index (PESI) tool did not accurately predict 30 day mortality in 230 patients with active cancer (Cstatistic, 0.565; 95\% CI, 0.453-0.677). Such results bring into question the utility of risk stratification tools for patients with pulmonary embolism (PE) and cancer. Thus, we sought to evaluate the performance of 3 cancer-specific (RIETE, POMPE-C, and criteria by Font et $\mathrm{al}^{14}$ ) and 3 generic (Hestia, PESI, and Geneva prognostic score [GPS]) risk stratification tools for predicting 30-day post-PE mortality in patients with active cancer.

\section{Methods}

This retrospective study included consecutive adult patients with PE with active cancer presenting to our institution between October 21, 2010, and January 31, 2014. Patients were identified using the computerized billing system, which contains information on demographic characteristics (age, sex, race), ICD-9-CM diagnosis and procedure codes, and discharge status.

To be eligible for inclusion, patients were required to have a diagnosis code for PE (ICD-9-CM code $415.1 x)$ in the primary position. We only included patients with objectively confirmed PE (via the review of imaging ${ }^{7,8}$ ) and active cancer (determined by chart review and defined as cancer under the care of an oncologist or metastatic disease ${ }^{14}$ ). Patients were included regardless of whether their PE was symptomatic or discovered incidentally (ie, found on imaging ordered for cancer workup or surveillance). Because this was a retrospective study, all patients were managed according to usual practice at our institution.

We obtained data necessary to classify patients as low or high risk for early mortality according to 6 risk stratification tools (RIETE, POMPE-C, Hes- tia, Font criteria, PESI, and GPS) ${ }^{1-3,14-16}$ by linking patients identified through the billing system to the hospital's electronic health record (EHR). Trained study personnel abstracted laboratory values and vital signs as close to the time of emergency department presentation as possible (but within 24 hours) using a standardized data collection form. We assessed the presence of comorbidities and recent clinical events at time of departure from the emergency department. Patients were classified as low risk for early mortality by each risk stratification tool according to published methods and as outlined in supplemental eAppendix 1 (available online with this article at JNCCN.org). ${ }^{1-3,14-16}$

The primary aim of this study was to evaluate the performance of each risk stratification tool for predicting 30-day all-cause mortality, which was determined by searches of the Social Security Death Index. ${ }^{17}$ Baseline characteristics (eg, demographics, prognostic factors) are described with counts/proportions for categorical data and means \pm standard deviations (SDs) for continuous data. For each set of risk stratification criteria, we calculated the proportion of patients categorized as low risk and determined the sensitivity, specificity, negative predictive value (NPV), and positive predictive value (PPV), along with $95 \%$ confidence intervals, of each tool for predicting mortality. Overall discriminative power was assessed using the C-statistic. Statistical analyses were performed using IBM SPSS Statistics version 22.0 (IBM Corporation, Armonk, NY). This study was approved by the Hartford Hospital Institutional Review Board with a waiver of informed consent.

\section{Results}

Of the 603 patients with objectively confirmed acute PE presenting to our hospital between October 21, 2010, and January 31, 2014, 124 had active cancer and were included in this analysis (Figure 1). The average patient age was 66.2 years $(\mathrm{SD}, 12.8)$; half $(\mathrm{n}=62)$ of the patients were male, $18(14.5 \%)$ were treated in an intensive care unit, and 8 (6.5\%) had confirmed PE discovered incidentally (Table 1 , supplemental eAppendix 2 and 3 ). Lung was the most common cancer type $(n=36 ; 29.0 \%)$, followed by genitourinary $(n=19$; $15.3 \%)$ and breast $(n=16 ; 12.9 \%)$. Concurrent deep vein thrombosis was found in $46 \%$ of patients. Approximately half (49.2\%) of the population had meta- 
Weeda et al

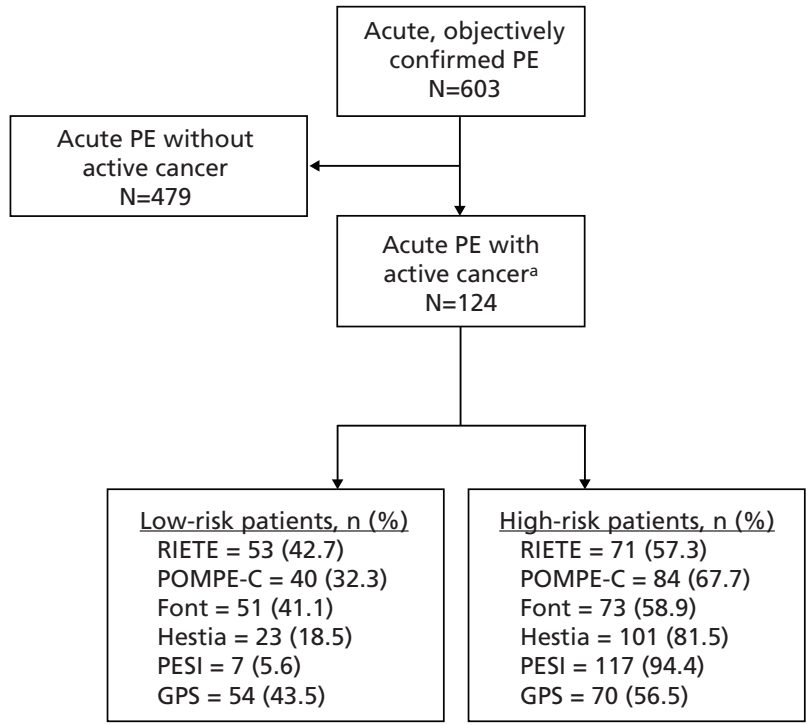

Figure 1. Identified patients with PE and active cancer via distribution of risk classes.

Abbreviations: GPS, Geneva prognostic score; PE, pulmonary embolism; PESI, Pulmonary Embolism Severity Index.

${ }^{\mathrm{a} A} \mathrm{~A}$ total of 8 patients $(6.5 \%)$ had confirmed PE discovered incidentally.

static disease; $52.4 \%$ were receiving treatment for their cancer (chemotherapy alone, $46.8 \%$; radiation alone, 16.9\%; concurrent chemotherapy and radiation, $11.3 \%)$. Predictor variables among included patients are depicted in Table 2.

All-cause mortality at 30-days was 20.2\% (25/124 patients). In terms of prognostication, the cancerspecific tools (POMPE-C, RIETE, and Font criteria) categorized between approximately $32 \%$ to $43 \%$ of patients as low risk, with sensitivities of $88.0 \%$ to $96.0 \%$, specificities of $38.4 \%$ to $52.5 \%$, NPVs of $94.1 \%$ to $98.1 \%$, and C-statistics of 0.723 to 0.806 for predicting mortality (Table 3). The generic PESI and Hestia tools also had high sensitivities (>96.0\%) but classified $<19 \%$ of patients as low risk. Specificity of these tools were low (PESI, 6.1\%; Hestia, 23.2\%); NPVs and C-statistics ranged from $85.7 \%$ to $100 \%$ and 0.725 to 0.754 , respectively. Although the final noncancer tool, GPS, classified $43.5 \%$ of patients as low risk, it did so with a low sensitivity $(52.0 \%)$, specificity (42.4\%), and C-statistic (0.483).

\section{Discussion}

In this real-world study of 124 patients with PE and active cancer, we report the results of 6 risk stratification tools: 3 cancer-specific (POMPE-C,

\begin{tabular}{|c|c|}
\hline Characteristic & $\begin{array}{c}\text { Total } \\
n(\%) \\
(\mathrm{N}=124)\end{array}$ \\
\hline Age, y $($ mean $\pm S D)$ & $66.2 \pm 12.8$ \\
\hline Male sex & $62(50.0)$ \\
\hline Current DVT & $58(46.8)$ \\
\hline Early discharge $^{a}$ & $31(25.0)$ \\
\hline PE managed in intensive care unit & $18(14.5)$ \\
\hline \multicolumn{2}{|l|}{ Cancer type } \\
\hline Lung & $36(29.0)$ \\
\hline Colorectal & $9(7.3)$ \\
\hline Pancreas & $4(3.2)$ \\
\hline Other gastrointestinal & $4(3.2)$ \\
\hline Breast & $16(12.9)$ \\
\hline Prostate & $12(9.7)$ \\
\hline Brain & $9(7.3)$ \\
\hline Hematologic & $6(4.8)$ \\
\hline Genitourinary & 19 (15.3) \\
\hline Other & $7(5.6)$ \\
\hline Unknown & $2(1.6)$ \\
\hline Metastatic disease ${ }^{b}$ & $61(49.2)$ \\
\hline Bone & $17(13.7)$ \\
\hline Central nervous system & $18(14.5)$ \\
\hline Liver & $14(11.3)$ \\
\hline Lung & $22(17.7)$ \\
\hline Other & $7(5.6)$ \\
\hline Unknown & $1(0.8)$ \\
\hline Receiving chemotherapy or radiation & $65(52.4)$ \\
\hline
\end{tabular}

Abbreviations: DVT, deep vein thrombosis; PE, pulmonary embolism. aDefined as within 72 hours of presentation.

bSome patients had metastatic disease in $>1$ location.

RIETE, and Font criteria) and 3 designed for use in a general PE population. The cancer-specific risk stratification tools demonstrated $>88 \%$ sensitivity for predicting 30-day all-cause mortality. With the exception of GPS (which displayed a sensitivity of $52 \%$ ), the generic tools also demonstrated high sensitivity $(>96 \%)$. These high sensitivity values indicate that the tools accurately risk stratify into the high-risk group most patients who die within 30 days of their index PE event. Perhaps the most notable difference between these tools was the percent of the population designated as low risk. The cancer-specific tools classified between 32\% (POMPE-C) and 40\% (Font and RIETE) into the low-risk group, whereas the generic PESI and Hestia classified $<20 \%$ at low risk. Specificity (the true negative rate) was low for all tools $(<53 \%)$, meaning that many patients who survive at 30 days receive an incorrect (and perhaps alarming) high-risk prognosis. Thus, the models may unnecessarily concern low-risk patients and the clinicians caring for them, leading to overtreatment. Interestingly, the 
PE Risk Stratification in Cancer

\begin{tabular}{|c|c|}
\hline Characteristic & $\begin{array}{c}\text { Total } \\
n(\%) \\
(\mathrm{N}=124) \\
\end{array}$ \\
\hline \multicolumn{2}{|l|}{ Demographic factors } \\
\hline Age $>80 y$ & $15(12.1)$ \\
\hline Body weight, $\mathrm{kg}(\operatorname{mean} \pm \mathrm{SD})$ & $84.1 \pm 23.2$ \\
\hline Body weight $<60 \mathrm{~kg}$ & $15(12.1)$ \\
\hline Male sex & $62(50.0)$ \\
\hline \multicolumn{2}{|l|}{ Clinical findings } \\
\hline Pulse, beats/min $($ mean $\pm S D)$ & $96.3 \pm 20.6$ \\
\hline Pulse $\geq 100$ beats $/ \mathrm{min}^{\mathrm{b}}$ & $57(46.0)$ \\
\hline Systolic blood pressure, $\mathrm{mm} \mathrm{Hg}($ mean $\pm \mathrm{SD})$ & $127.6 \pm 20.9$ \\
\hline Systolic blood pressure $<100 \mathrm{~mm} \mathrm{Hg}$ & $15(12.1)$ \\
\hline Respiratory rate, ${ }^{b}$ breaths/min (mean $\left.\pm S D\right)$ & $19.0 \pm 2.8$ \\
\hline Respiratory rate $\geq 30$ breaths $/ \mathrm{min}$ & $1(0.8)$ \\
\hline $\mathrm{O}_{2}$ saturation, $\%($ mean $\pm \mathrm{SD})$ & $96.1 \pm 3.7$ \\
\hline $\mathrm{O}_{2}$ saturation $<90 \%$ & $8(6.5)$ \\
\hline $\begin{array}{l}\text { Supplemental oxygen needed to main } \mathrm{O}_{2} \text { saturation } \\
>90 \% \text { for }>24 \text { hours }\end{array}$ & $69(55.6)$ \\
\hline Temperature, ${ }^{\circ} \mathrm{C}($ mean $\pm \mathrm{SD})$ & $36.5 \pm 0.7$ \\
\hline Temperature $<36^{\circ} \mathrm{C}$ & $25(20.2)$ \\
\hline Creatinine clearance $<30 \mathrm{~mL} / \mathrm{min}$ & $2(1.6)$ \\
\hline Platelet count $\leq 50,000 / \mathrm{mm}^{3}$ & $1(0.8)$ \\
\hline \multicolumn{2}{|l|}{ Clinical comorbidities and variables } \\
\hline Chronic lung disease & $36(29.0)$ \\
\hline Heart failure & $6(4.8)$ \\
\hline Hemodynamically unstable ${ }^{c}$ & $21(16.9)$ \\
\hline $\begin{array}{l}\text { Thrombolysis or embolectomy }<48 \text { hours of } \\
\text { presentation }\end{array}$ & $4(3.2)$ \\
\hline Active bleeding & $3(2.4)$ \\
\hline High risk for bleeding ${ }^{d}$ & $15(12.1)$ \\
\hline PE on anticoagulation & $11(8.9)$ \\
\hline Need for intravenous pain medication for $>24$ hours & $9(7.3)$ \\
\hline Medical or social reason for admission ${ }^{\mathrm{e}}$ & $63(50.8)$ \\
\hline Severe liver impairment ${ }^{f}$ & $2(1.6)$ \\
\hline Renal disease & $4(3.2)$ \\
\hline History of heparin-induced thrombocytopenia & $1(0.8)$ \\
\hline Immobility ${ }^{9}$ & $9(7.3)$ \\
\hline Altered mental status & $10(8.1)$ \\
\hline Respiratory distress $^{h}$ & $93(75.0)$ \\
\hline Do not resuscitate status & $10(8.1)$ \\
\hline Unilateral limb swellingi & $11(8.9)$ \\
\hline History of DVT & $8(6.5)$ \\
\hline Current DVT & $58(46.8)$ \\
\hline Metastatic disease & $61(49.2)$ \\
\hline
\end{tabular}

Abbreviations: DVT, deep vein thrombosis; $\mathrm{O}_{2}$, oxygen; $\mathrm{PE}$, pulmonary embolism.

a Of the 124 patients, $1(0.8 \%)$ had unknown values for respiratory rate, temperature, and platelets. No patients had missing values for pulse, systolic blood pressure, $\mathrm{O}_{2}$ saturation, temperature, or glomerular filtration rate (creatinine clearance estimate).

${ }^{b}$ For purposes of POMPE-C scoring, this value was taken within 6 hours to remain consistent with the derivation study.

cPulse $\geq 100$ beats/min and systolic blood pressure $\leq 100 \mathrm{~mm} \mathrm{Hg}$ or condition requiring admission to an intensive care unit.

${ }^{\mathrm{d}}$ Gastrointestinal bleeding in the preceding 14 days, stroke in the preceding 4 weeks, procedure in the preceding 2 weeks, bleeding disorder or thrombocytopenia (platelet count $<75 \times 109 / \mathrm{L}$ ), or uncontrolled hypertension (systolic blood pressure $>180 \mathrm{~mm} \mathrm{Hg}$ or diastolic blood pressure $>110 \mathrm{~mm} \mathrm{Hg}$ ).

eMedical or social reason for hospital treatment was determined by trained study personnel using all data available in the electronic health record, including vital signs, laboratory values, and emergency department, admission, and consult notes.

tPresence of cirrhosis.

gNonsurgical patients assigned to bed rest for $\geq 4$ days in the past 2 months.

hObvious anxiety from dyspnea, evidence of increased work of breathing, or the use of $\mathrm{O}_{2}$ before or immediately upon arrival to the emergency room.

'Leg or arm that has new, presently noticeable swelling, causing it to be asymmetrical compared with the contralateral limb.

jSome patients had metastatic disease in $>1$ location. cancer-specific tools did exhibit numerically higher specificity $(38 \%-53 \%)$ compared with the generic PESI and Hestia (6\% and 23\%, respectively).

Although a perfect risk stratification tool would be both $100 \%$ sensitive and specific, there is an inherent trade-off between the 2 measures. Given the clinical goal to "do no harm," high sensitivity when making a decision to discharge early from the hospital or continue treatment as an outpatient is preferable to high specificity. Misclassifying patients in this setting has an asymmetric impact, given that the most important concern is not that low-risk patients may have a longer than needed hospital stay but that high-risk patients may inappropriately receive reductions in supportive care. In prospective studies using variations of the Hestia criteria (eg, absence of active bleeding, a requirement for intravenous pain medication, or other medical reasons for hospital admission) to select patients with acute PE and active cancer for outpatient treatment, all-cause mortality was observed in 3\% and $30.5 \%$ of low-risk patients at 30 days and 6 months, respectively. ${ }^{14,18}$ In patients with active cancer, selecting those at low risk for all-cause mortality at $\geq 30$ days is challenging, because these patients may experience mortality not only from their acute PE but also due to cancer progression. In the EPIPHANY registry (a multicenter registry in Spain comprising patients with $\mathrm{PE}$ and active cancer), more than half of the deaths at 15 days were due to cancer or comorbidities other than PE. ${ }^{19}$ Although PE risk stratification is historically based on the risk of 30-day all-cause mortality, ${ }^{14-16}$ it has been suggested that patients with PE and active cancer could be selected for outpatient management based on their risk of other outcomes (eg, PE complications such as recurrent VTE or major bleeding). ${ }^{19}$ This strategy is further supported by the fact that it may be desirable to treat patients receiving palliative care (who may experience early mortality from cancer progression) as outpatients. ${ }^{19}$

The prognostic performance of PE risk stratification tools among patients with active cancer in our validation is consistent with previous findings. ${ }^{1-3,13-16}$ In the cancer-only internal validation studies, POMPE-C classified $27 \%$ of patients as low risk with a sensitivity of $100 \%$, RIETE classified $22 \%$ as low risk with a sensitivity of $100 \%$, whereas the criteria by Font et $\mathrm{al}^{14}$ classified $45 \%$ as low risk with a sensitivity of $88 \% .{ }^{14-16}$ In contrast, GPS and 
Weeda et al

\begin{tabular}{|c|c|c|c|c|c|c|}
\hline \multirow[b]{2}{*}{ Characteristic } & \multicolumn{3}{|c|}{ Cancer-Specific Risk Stratification Tools } & \multicolumn{3}{|c|}{ Generic Risk Stratification Tools } \\
\hline & RIETE & POMPE-C & Font & Hestia & PESI & GPS \\
\hline Low risk, n (\%) & $\begin{array}{c}53 \\
(42.7 \%)\end{array}$ & $\begin{array}{c}40 \\
(32.3 \%)\end{array}$ & $\begin{array}{c}51 \\
(41.1 \%)\end{array}$ & $\begin{array}{c}23 \\
(18.5 \%)\end{array}$ & $\begin{array}{c}7 \\
(5.6 \%)\end{array}$ & $\begin{array}{c}54 \\
(43.5 \%)\end{array}$ \\
\hline Low-risk mortality, n/N (\%) & $\begin{array}{c}1 / 53 \\
(1.9 \%)\end{array}$ & $\begin{array}{c}2 / 40 \\
(5.0 \%)\end{array}$ & $\begin{array}{c}3 / 51 \\
(5.9 \%)\end{array}$ & $\begin{array}{l}0 / 23 \\
(0 \%)\end{array}$ & $\begin{array}{c}1 / 7 \\
(14.3 \%)\end{array}$ & $\begin{array}{c}12 / 54 \\
(22.2 \%)\end{array}$ \\
\hline High-risk mortality, n/N (\%) & $\begin{array}{c}24 / 71 \\
(33.8 \%)\end{array}$ & $\begin{array}{c}23 / 84 \\
(27.4 \%)\end{array}$ & $\begin{array}{c}22 / 73 \\
(30.1 \%)\end{array}$ & $\begin{array}{l}25 / 101 \\
(24.8 \%)\end{array}$ & $\begin{array}{l}24 / 117 \\
(20.5 \%)\end{array}$ & $\begin{array}{c}13 / 70 \\
(18.6 \%)\end{array}$ \\
\hline $\begin{array}{l}\text { Sensitivity, \% } \\
(95 \% \mathrm{Cl})\end{array}$ & $\begin{array}{c}96.0 \% \\
(77.7 \%-99.8 \%)\end{array}$ & $\begin{array}{c}92.0 \% \\
(72.5 \%-98.6 \%)\end{array}$ & $\begin{array}{c}88.0 \% \\
(67.7 \%-96.8 \%)\end{array}$ & $\begin{array}{c}100 \% \\
(83.4 \%-100 \%)\end{array}$ & $\begin{array}{c}96.0 \% \\
(77.7 \%-99.8 \%)\end{array}$ & $\begin{array}{c}52.0 \% \\
(31.8 \%-71.7 \%)\end{array}$ \\
\hline $\begin{array}{l}\text { Specificity, \% } \\
(95 \% \mathrm{Cl})\end{array}$ & $\begin{array}{c}52.5 \% \\
(42.3 \%-62.6 \%)\end{array}$ & $\begin{array}{c}38.4 \% \\
(28.9 \%-48.7 \%)\end{array}$ & $\begin{array}{c}48.5 \% \\
(38.4 \%-58.7 \%)\end{array}$ & $\begin{array}{c}23.2 \% \\
(15.6 \%-33.0 \%)\end{array}$ & $\begin{array}{c}6.1 \% \\
(2.5 \%-13.2 \%)\end{array}$ & $\begin{array}{c}42.4 \% \\
(32.7 \%-52.8 \%)\end{array}$ \\
\hline $\begin{array}{l}\text { NPV } \\
(95 \% \mathrm{Cl})\end{array}$ & $\begin{array}{c}98.1 \% \\
(88.6 \%-99.9 \%)\end{array}$ & $\begin{array}{c}95.0 \% \\
(81.8 \%-99.1 \%)\end{array}$ & $\begin{array}{c}94.1 \% \\
(82.8 \%-98.5 \%)\end{array}$ & $\begin{array}{c}100 \% \\
(82.2 \%-100 \%)\end{array}$ & $\begin{array}{c}85.7 \% \\
(42.0 \%-99.2 \%)\end{array}$ & $\begin{array}{c}77.8 \% \\
(64.1 \%-87.5 \%)\end{array}$ \\
\hline $\begin{array}{l}\text { PPV } \\
(95 \% \mathrm{Cl})\end{array}$ & $\begin{array}{c}33.8 \% \\
(23.3 \%-46.1 \%)\end{array}$ & $\begin{array}{c}27.4 \% \\
(18.5 \%-38.4 \%)\end{array}$ & $\begin{array}{c}30.1 \% \\
(20.2 \%-42.1 \%)\end{array}$ & $\begin{array}{c}24.8 \% \\
(16.9 \%-34.5 \%)\end{array}$ & $\begin{array}{c}20.5 \% \\
(13.8 \%-29.2 \%)\end{array}$ & $\begin{array}{c}18.6 \% \\
(10.6 \%-30.0 \%)\end{array}$ \\
\hline $\begin{array}{l}\text { C-statistic } \\
(95 \% \mathrm{Cl})\end{array}$ & $\begin{array}{c}0.774 \\
(0.679-0.870)\end{array}$ & $\begin{array}{c}0.806 \\
(0.713-0.899)\end{array}$ & $\begin{array}{c}0.723 \\
(0.616-0.813)\end{array}$ & $\begin{array}{c}0.725 \\
(0.623-0.827)\end{array}$ & $\begin{array}{c}0.754 \\
(0.630-0.878)\end{array}$ & $\begin{array}{c}0.483 \\
(0.353-0.614)\end{array}$ \\
\hline
\end{tabular}

Abbreviations: GPS, Geneva prognostic score; NPV, negative predictive value; PESI, Pulmonary Embolism Severity Index; PPV, positive predictive value.

PESI have shown a poor ability to appropriately risk score $\mathrm{PE}$ in populations with active cancer at low risk of early mortality. ${ }^{13,16}$ For instance, in an external validation, GPS classified $55 \%$ of patients with PE and active cancer as low risk but displayed a sensitivity of $60 \% .{ }^{14}$ In the same validation, PESI displayed a high sensitivity (93\%) but only classified $8 \%$ of patients as low risk. This may be due to the inclusion of cancer as a component of risk assessment in both PESI and GPS.

In our analysis, the generic Hestia criteria was scored using the tool's original components; however, several studies have assessed adapted versions of this criteria in patients with PE and active cancer. ${ }^{1,14,19,20}$ In an analysis of 585 patients from the EPIPHANY registry, Hestia-like criteria displayed a sensitivity of $99.2 \%$ (95\% CI, 95.6\%-99.9\%) for prognosticating 30-day mortality. ${ }^{20}$ When studied in a larger cohort from this registry $(n=1,075)$, patients that had 0 versus $\geq 1$ of these criteria had a lower odds of mortality at 15 -days (odds ratio [OR], 0.13; 95\% CI, 0.07-0.25). ${ }^{19}$ All the criterion contained within Font et $\mathrm{al}^{14}$ are utilized in some form in the Hestia criteria, with only minor differences between the 2 sets of criteria. ${ }^{1,14}$ Despite their similarities, there was an approximately 2 -fold difference in the number of patients deemed low risk by the Font criteria versus Hestia in our study. The most common reason patients were classified as high risk by Hestia but not the Font criteria was the requirement for oxygen $\left(\mathrm{O}_{2}\right)$ therapy to maintain an $\mathrm{O}_{2}$ saturation $>90 \%$ for $>24$ hours. Font et $\mathrm{al}^{14}$ (along with various other tools such as PESI and GPS) use $\mathrm{O}_{2}$ saturation values in PE risk stratification rather than the requirement for $\mathrm{O}_{2}$ therapy. Because both of these criteria attempt to capture the same characteristic (ie, low $\mathrm{O}_{2}$ levels), it is unlikely that this observed difference is clinically meaningful.

A risk stratification tool is only as good as its implementation by clinicians in practice. Although some clinicians prioritize pragmatic eligibility criteria, ${ }^{16}$ others prefer multivariate prognostic scores, which often optimize validity. ${ }^{15}$ Completion of a tool is time-consuming, which may be attenuated by a pragmatic approach. In the derivation of RIETE, despite renal impairment and leukocytosis being significantly associated with mortality, the authors chose to exclude these values from the final tool in order to maintain usability; they did so with a minimal drop in the C-statistic (eg, a decrease to 0.76 vs 0.78). ${ }^{16}$ Although GPS and the Font criteria contain specific laboratory parameters, the tools consist of only 6 and 7 criteria, respectively ${ }^{3,14}$; PESI and Hestia each consist of 11 criteria. $^{1,2}$ POMPE-C consists of an equation not easily computed without the use of a calculator. ${ }^{15}$ On the contrary, it could be argued that more simplified scores represent a decrease in precision. In the derivation of POMPE-C, dichotomizing variables (ie, respiratory rate, pulse oximetry, and body weight) in an attempt to simplify the rule caused a decrease in both precision and accuracy. Therefore, it was prudent of the authors to publish the tool as an equation. ${ }^{15}$ Of note, a Web-based version of 
PE Risk Stratification in Cancer

POMPE-C was created (https://www.mdcalc.com/ pompe-c-tool-pulmonary-embolism-mortality), which may, with the increasing use of electronic resources, encourage its uptake in clinical practice.

It has been suggested that PE risk stratification tools can aid in the selection of low-risk patients who may qualify for outpatient management. ${ }^{2}$ Several studies have evaluated outpatient treatment of PE in patients with active cancer. ${ }^{14,18}$ Siragusa et $\mathrm{al}^{18}$ prospectively evaluated 68 patients with $\mathrm{PE}$ and active cancer and selected 36 patients for home treatment based on the absence of active bleeding, a requirement for intravenous pain medication or other medical reasons for hospital admission. Compared with the inpatients, those treated as outpatients did not have higher rates of VTE $(9.3 \%$ vs $5.5 \%$ ), major bleeding ( $0 \%$ vs $2.7 \%$ ), or death $(37.0 \%$ vs $30.5 \%)$ at 6 months $(P>.05$ for all). In another study of 138 patients with $\mathrm{PE}$ and active cancer, 62 were prospectively selected for outpatient management using the Font criteria; no outpatient PEs required readmission due complications from their index event. ${ }^{14}$

Further studies are needed to address important questions in PE risk stratification in the setting of active cancer. First, the use of biomarkers (eg, cardiac troponins and natriuretic peptides) and imaging (eg, echocardiogram or CT) for right ventricular dysfunction in conjunction with cancer-specific risk stratification tools should be explored. Unlike clinical tools, which identify both a high-risk group that requires more aggressive care and a low-risk group that may qualify for deescalation of treatment, biomarkers and imaging were originally studied to identify patients with PE who might benefit from thrombolysis and embolectomy. ${ }^{21}$ Right ventricular dysfunction or myocardial injury on presentation for acute PE has been associated with an increased risk of mortality, ${ }^{22}$ and thus biomarkers and imaging may complement risk stratification tools. Moreover, future studies should be in the form of prospective clinical trials. The cancer-specific POMPE-C and REITE tools were derived using data from observational registries. ${ }^{15,16}$ Although these real-world data provide a high degree of applicability and allowed the authors to minimize selection bias (through the inclusion of consecutively identified patients with PE with minimal exclusion crite- ria), these registries (much like our own analysis) were not designed to directly evaluate the impact of risk stratification tools on outpatient treatment of low-risk PE.

Another emerging area of interest is incidentally identified PE, ${ }^{23-26}$ given that VTE is found in approximately $2.5 \%$ of patients undergoing staging imaging for cancer. ${ }^{23}$ When compared with symptomatic events, incidental PE is associated with a better prognosis (but with similar rates of recurrent VTE). ${ }^{25,26}$ For instance, in an analysis of the multicenter EPIPHANY registry $(n=1,033)$, patients with symptomatic PE had higher allcause 30-day mortality than those who had PE detected on imaging performed for reasons other than PE suspicion (OR, 1.98; 95\% CI, 1.25-3.11); no difference in VTE recurrence was observed. ${ }^{26}$ The RIETE and POMPE-C tools were specifically developed for symptomatic events, ${ }^{15,16}$ whereas approximately $47 \%$ of patients had incidentally detected PE in Font et al. ${ }^{14}$ Because these tools were intended for patients with PE with differing characteristics on presentation, it is difficult to compare them on "equal terms." Only 8 patients $(6.5 \%)$ in our analysis had their PE discovered incidentally, and thus we could not evaluate the prognostic characteristics of the tools in this subgroup. Such patients may have been underrepresented in our analysis, because $>50 \%$ of patients with PE and active cancer in recent registry studies had their event discovered incidentally. ${ }^{26}$

This study has other limitations that merit discussion. First, our sample size, and thus number of observed events $(n=25)$, was small. It has been suggested that $\geq 100$ events are needed to detect differences in external validations of predictive logistic regression models. ${ }^{27}$ Nonetheless, data on the use of PE risk stratification tools in patients with cancer are scarce. Second, our analysis was retrospective and we could not account for clinical gestalt, which providers frequently use to classify patients with low-risk PE in prospective settings. For instance, 1 patient who underwent thrombolysis within 48 hours of their index event was categorized as low risk by both RIETE and POMPE-C, and 1 patient in the RIETE low-risk category had active bleeding at presentation. Although these patients were alive at 30 days and thus did not impact the prognostic measures of 
Weeda et al

the rules, it is unlikely that they would be categorized as low risk according to clinical gestalt. Further, we only had access to patient data during their index PE stay and lacked information on outpatient follow-up and treatment or subsequent readmissions. Therefore, morbidity data (eg, major bleeding or recurrent VTE readmission) were not available. Lastly, our data were obtained from a single center, limiting generalizability.

\section{Conclusions}

When risk-stratifying newly diagnosed $\mathrm{PE}$ in patients with active cancer, cancer-specific tools appeared to exhibit better prognostic accuracy than their generic counterparts. POMPE-C, RIETE, and the criteria by Font et $\mathrm{al}^{14}$ identified a substantially greater proportion of patients with PE likely to survive to 30 days, with comparable sensitivity to the generic tools.

\section{References}

1. Zondag W, den Exter PL, Crobach MJ, et al. Comparison of two methods for selection of out of hospital treatment in patients with acute pulmonary embolism. Thromb Haemost 2013;109:47-52.

2. Aujesky D, Obrosky DS, Stone RA, et al. Derivation and validation of a prognostic model for pulmonary embolism. Am J Respir Crit Care Med 2005;172:1041-1046.

3. Wicki J, Perrier A, Perneger TV, et al. Predicting adverse outcome in patients with acute pulmonary embolism: a risk score. Thromb Haemost 2000;84:548-552.

4. Wells PS, Anderson DR, Bormanis J, et al. Value of assessment of pretest probability of deep-vein thrombosis in clinical management. Lancet 1997;350:1795-1798.

5. Kohn CG, Mearns ES, Parker MW, et al. Prognostic accuracy of clinical prediction rules for early post-pulmonary embolism all-cause mortality: a bivariate meta-analysis. Chest 2015;147:1043-1062.

6. Coleman CI, Peacock WF, Fermann GJ, et al. External validation of a multivariable claims-based rule for predicting in-hospital mortality and 30-day post-pulmonary embolism complications. BMC Health Serv Res 2016;16:610.

7. Kearon C, Akl EA, Ornelas J, et al. Antithrombotic therapy for VTE disease: CHEST Guideline and Expert Panel report. Chest 2016;149:315_ 352.

8. Konstantinides SV, Torbicki A, Agnelli G, et al. 2014 ESC guidelines on the diagnosis and management of acute pulmonary embolism. Eur Heart J 2014;35:3033-3069.

9. Spencer FA, Goldberg RJ, Lessard D, et al. Factors associated with adverse outcomes in outpatients presenting with pulmonary embolism: the Worcester Venous Thromboembolism Study. Circ Cardiovasc Qual Outcomes 2010;3:390-394.

10. Laporte S, Mismetti $\mathrm{P}$, Decousus $\mathrm{H}$, et al. Clinical predictors for fatal pulmonary embolism in 15520 patients with venous thromboembolism: findings from the Registro Informatizado de la Enfermedad TromboEmbolica venosa (RIETE) registry. Circulation 2008;117:1711-1716.

11. Dasta JF, Pilon D, Mody SH, et al. Daily hospitalization costs in patients with deep vein thrombosis or pulmonary embolism treated with anticoagulant therapy. Thromb Res 2015;135:303-310.

12. Weeda ER, Wells PS, Peacock WF, et al. Hospital length-of-stay and costs among pulmonary embolism patients treated with rivaroxaban versus parenteral bridging to warfarin. Intern Emerg Med 2017;12:311-318.

13. Ahn S, Lee YS, Kim WY, et al. Prognostic value of treatment setting in patients with cancer having pulmonary embolism: comparison with the Pulmonary Embolism Severity Index. Clin Appl Thromb Hemost 2017;23:615-621.

14. Font C, Carmona-Bayonas A, Fernández-Martinez A, et al. Outpatient management of pulmonary embolism in cancer: data on a prospective cohort of 138 consecutive patients. J Natl Compr Canc Netw 2014;12:365373.

15. Kline JA, Roy PM, Than MP, et al. Derivation and validation of a multivariate model to predict mortality from pulmonary embolism with cancer: the POMPE-C tool. Thromb Res 2012;129:e194-199.

16. den Exter PL, Gómez V, Jiménez D, et al. A clinical prognostic model for the identification of low-risk patients with acute symptomatic pulmonary embolism and active cancer. Chest 2013;143:138-145.

17. Social Security Death Master File. Available at: https://www.ssdmf.com/. Accessed August 2, 2015.

18. Siragusa S, Arcara C, Malato A, et al. Home therapy for deep vein thrombosis and pulmonary embolism in cancer patients. Ann Oncol 2005;16(Suppl 4):iv136-139.

19. Carmona-Bayonas A, Jiménez-Fonseca $\mathrm{P}$, Font C, et al. Predicting serious complications in patients with cancer and pulmonary embolism using decision tree modelling: the EPIPHANY Index. $\mathrm{Br} \mathrm{J}$ Cancer 2017;116:994-1001.

20. Carmona-Bayonas A, Font C, Jiménez-Fonseca P, et al. On the necessity of new decision-making methods for cancer-associated, symptomatic pulmonary embolism. Thromb Res 2016;143:76-85.

21. Giannitsis E, Katus HA. Biomarkers for clinical decision-making in the management of pulmonary embolism. Clin Chem 2017;63:91-100.

22. Sanchez O, Trinquart L, Colombet I, et al. Prognostic value of right ventricular dysfunction in patients with haemodynamically stable pulmonary embolism: a systematic review. Eur Heart J 2008;29:1569-1577.

23. Douma RA, Kok MG, Verberne LM, et al. Incidental venous thromboembolism in cancer patients: prevalence and consequence. Thromb Res 2010;125:e306-309.

24. Peris M, Jiménez D, Maestre A, et al. Outcome during and after anticoagulant therapy in cancer patients with incidentally found pulmonary embolism. Eur Respir J 2016;48:1360-1368.

25. van der Hulle T, den Exter PL, Planquette B, et al. Risk of recurrent venous thromboembolism and major hemorrhage in cancer-associated incidental pulmonary embolism among treated and untreated patients: a pooled analysis of 926 patients. J Thromb Haemost 2016;14:105-113.

26. Font $\mathrm{C}$, Carmona-Bayonas $\mathrm{A}$, Beato $\mathrm{C}$, et al. Clinical features and short-term outcomes of cancer patients with suspected and unsuspected pulmonary embolism: the EPIPHANY study. Eur Respir J 2017;49:1600282

27. Vergouwe Y, Steyerberg EW, Eijkemans MJ, Habbema JD. Substantial effective sample sizes were required for external validation studies of predictive logistic regression models. J Clin Epidemiol 2005;58:475-483.

\section{See JNCCN.org for supplemental online content.}

